\title{
Occurrence of Virulence Genes and Antimicrobial Resistance of E. coli O157:H7 Isolated from the Beef Carcass of Bahir Dar City, Ethiopia
}

\author{
Habtamu Yalew Ayenew, ${ }^{1}$ Birhan Agmas Mitiku $\mathbb{D}^{1},{ }^{1}$ and Tesfaye Sisay Tesema ${ }^{2}{ }^{2}$ \\ ${ }^{1}$ Department of Veterinary Science, College of Agriculture and Environmental Science, Bahir Dar University, Bahir Dar, Ethiopia \\ ${ }^{2}$ Institute of Biotechnology, Addis Ababa University, Addis Ababa, Ethiopia
}

Correspondence should be addressed to Birhan Agmas Mitiku; mitikuagmas@gmail.com

Received 10 May 2021; Accepted 26 August 2021; Published 18 September 2021

Academic Editor: Nora Mestorino

Copyright (C) 2021 Habtamu Yalew Ayenew et al. This is an open access article distributed under the Creative Commons Attribution License, which permits unrestricted use, distribution, and reproduction in any medium, provided the original work is properly cited.

E. coli $\mathrm{O} 157: \mathrm{H} 7$ is one of the most virulent foodborne pathogens. The aim of this study was to isolate E. coli $\mathrm{O} 157: \mathrm{H} 7$, determine virulence genes carried by the organism, and assess the antimicrobial susceptibility pattern of the isolates from beef carcass samples at Bahir Dar city. Swab samples $(n=280)$ were collected from the carcass of cattle slaughtered at the abattoir and processed using sorbitol MacConkey agar supplemented with cefixime telluride and confirmed with latex agglutination test. A polymerase chain reaction was performed on isolates for the detection of virulence genes stx 1, stx $2, h l y A$, and eae. Antimicrobial susceptibility testing was performed using the disk diffusion method. Of 280 samples processed, 25 (8.9\%) isolates were positive. Out of 25 isolates subjected for molecular detection, $8(32 \%)$ and $14(56 \%)$ isolates possessed stx 1 and stx2 genes, respectively; from those, 5 (20\%) isolates had both genes for the production of Shiga toxins. Compared from other virulent genes relatively higher proportion of $18(72 \%)$ isolates carried the hlyA gene. Only $5(2 \%)$ isolates were positive for eae. Resistance was detected in all $25(100 \%)$ isolates and $3(12 \%)$ against clindamycin and trimethoprim, respectively. This study result highlights the potential threat to public health. The abattoir workers need to be aware about the pathogen and should follow appropriate practices to prevent contamination of meat intended for human consumption.

\section{Background}

Foodborne pathogens are one of the leading causes of illness and death worldwide. They exert heavy burden costing billions of dollars in medical care, social costs, and overall economic and infrastructure effects of countries [1-3]. Developing countries including Ethiopia are more vulnerable to foodborne illnesses mainly due to the lack of awareness regarding safe and hygienic food practices [4]. About 2 million people die per year due to diseases of foodborne pathogens in developing countries including Ethiopia $[2,4]$.

Among the pathogenic E. coli strains, enterohemorrhagic E. coli $\mathrm{O} 157: \mathrm{H7}$ is one of the most virulent foodborne strains which is the leading cause of hemorrhagic colitis (HC), hemolytic uremic syndrome (HUS), and thrombotic thrombocytopenic purpura (TTP) in human beings. These illnesses may lead to death due to improper absorption of nutrients and destruction of certain tissues in the target organs $[5,6]$. The ability to produce one or more Shiga toxins is a hallmark of E. coli O157:H7 infection [7].

Shiga toxins are a family of related toxins with two major groups, Shiga toxin 1 (stx1) and Shiga toxin 2 (stx2), expressed by genes considered to be horizontally acquired by bacteriophages, and are encoded by stx 1 and stx 2 genes, respectively [5, 8]. In addition, enterohemolysin [9] and intimin [10], encoded by $h l y A$ and eae genes, respectively, are another form of virulence factors of the bacteria [7].

It is estimated that Shiga toxin-producing E. coli (STEC) causes 2,801,000 acute illnesses each year worldwide and may cause 3,890 cases of HUS and 270 cases of end-stage renal disease $[3,11]$. 
Cattle are the primary reservoirs of E. coli O157:H7, and ground beef and beef products are identified as major sources of foodborne transmission. Carcass contamination occurs through skin to carcass or fecal to carcass transfer of the pathogen during the slaughter process at processing plants $[12,13]$. The process of removing the gastrointestinal tract during slaughtering of food animals is regarded as one of the most important sources of carcass and organ contamination with bacteria at abattoirs [14]. In addition to being gastrointestinal contamination sources, lymph nodes left at carcass also serve as niches of E. coli O157:H7 persistence, thus sources of carcass contamination [15].

The clinical significance and economic burden associated with outbreaks caused by E. coli O157:H7 have led to the development of a variety of detection methods. These include the application of conventional bacteriological methods using selective media such as sorbitol MacConkey agar or chromogenic agar, which usually take several days to complete, and molecular-based assays such as polymerase chain reaction- (PCR-) based methods, microarray, and whole genomic sequencing. Of these molecular methods, PCR is a commonly used method [16].

The use of antimicrobial agents in the treatment of E. coli O157:H7 infection is not recommended but remains a debatable issue. This is based on studies that have shown it to be a risk factor for the development of HUS [7]. Besides, the emergence of antibiotic-resistant bacteria and their resistance genes has turned into a serious growing issue in current medications [17].

In Ethiopia, foodborne disease is a common problem. This is due to the prevailing poor food handling and sanitation practices, inadequate food safety laws, weak regulatory systems, lack of financial resources to invest in safer equipment, and lack of education for food handlers $[4,18]$. In addition to that animals are commonly slaughtered and dressed under unhygienic conditions, this further compromises the microbiological quality and safety of meat obtained from the animals. The magnitude of contamination may vary from area to area based on the management of slaughtering practice $[19,20]$. However, only very few studies can be found regarding E. coli O157:H7 in animals, animal products, or people in Ethiopia [13, 20, 21].

As far as our knowledge is concerned, few data were available in Bahir Dar regarding carcass contamination of $E$. coli O157:H7 during the slaughtering process. The lack of vigorous surveillance of the pathogen in Ethiopia meat and meat products presents a challenge for risk-based approaches to improve food safety as it becomes difficult to demonstrate the magnitude of contamination with this pathogen during the slaughtering process. There is a need to generate more data regarding E. coli O157:H7 from abattoirs by taking samples from the sites of the carcass which are more prone to contamination (i.e., the abdomen (flank), thorax (lateral), and breast (lateral)) during the slaughtering process.

The current accepted standard procedure for E. coli O157:H7 identification is amplification of stx1, stx2, eae, and $h l y A$ by PCR $[21,22]$. PCR has gained more acceptance and use due to its ability to differentiate and reliability. In addition, various target genes have been used in the PCR detection scheme for the pathogen [16]. However, very few studies can be found regarding identification of the bacteria based on the detection of virulence genes in Ethiopia [6], and little work was done in the Bahir Dar municipal abattoir or any slaughtering areas at Bahir Dar and its environs.

The misuse of antimicrobial agents for farming and therapeutic purposes in animals and humans is the main cause of the emergence and transmission of antibiotic-resistant strains, which are very difficult to treat with commonly used antibiotics, to humans via the food supply chain [9]. Antimicrobial resistance among enteric bacteria is an increasing global public health concern. The widespread administration of antimicrobials promotes the selection of antimicrobial-resistant strains, which complicates the treatment of bacterial infections [23]. To our knowledge, there are few reports on the antibiotic resistance status of $E$. coli O157:H7 isolated from the abattoir in Ethiopia, and few studies have been carried out in Bahir Dar. Therefore, surveillance of antimicrobial resistance in E. coli O157:H7 is very important for preventing the spread of antimicrobial resistance in organisms and future disease management.

The aim of this study was to investigate the presence of the E. coli $\mathrm{O} 157$ strain in the carcass of cattle slaughtered at the Bahir Dar municipal abattoir, examine the presence of stx 1 , stx 2 , eae, and $h l y A$ genes, evaluate the antimicrobial resistance of the isolates, and assess knowledge, attitude, and practice of abattoir workers towards food safety.

\section{Methods}

2.1. Description of the Study Area. The study was conducted at Bahir Dar city. Bahir Dar city is in the northwestern part of Ethiopia, $565 \mathrm{~km}$ away from Addis Ababa at latitude $11^{\circ} 35^{\prime} 37.10^{\prime \prime} \mathrm{N}$ and longitude $37^{\circ} 23^{\prime} 26.77^{\prime \prime} \mathrm{E}$ on the south of Lake Tana, the upper water shed of the Blue Nile River (Figure 1) [24]. Cattle slaughtered at the Bahir Dar city abattoir are mainly of the zebu type and originated from different districts of northwest Ethiopia [25].

2.2. Study Design and Sampling Techniques. A cross-sectional study design was conducted from December 2019 to August 2020. Systematic random sampling at the abattoir was carried out to select the beef carcass. A swab was taken from the area of the carcass which was exposed for contamination during the slaughtering process. A total of 280 samples were taken to increase the probability of acquiring many isolates of the bacteria from the carcass.

The selected carcasses were swabbed using the method described in [26]. Sterile cotton-tipped swab $(2 \times 3 \mathrm{~cm})$, fitted with shaft soaked with approximately $10 \mathrm{ml}$ of buffered peptone water, was rubbed horizontally first and then vertically several times on the carcasses. The abdomen (flank), thorax (lateral), and breast (lateral) were sites selected for the occurrence of contamination and thus for sampling using swabbing [26]. All the swab samples were put inside the test tube. The samples for the study were collected under strict aseptic procedures and then were transported in an ice box to the Amhara Public Health Institute Microbiology Laboratory 

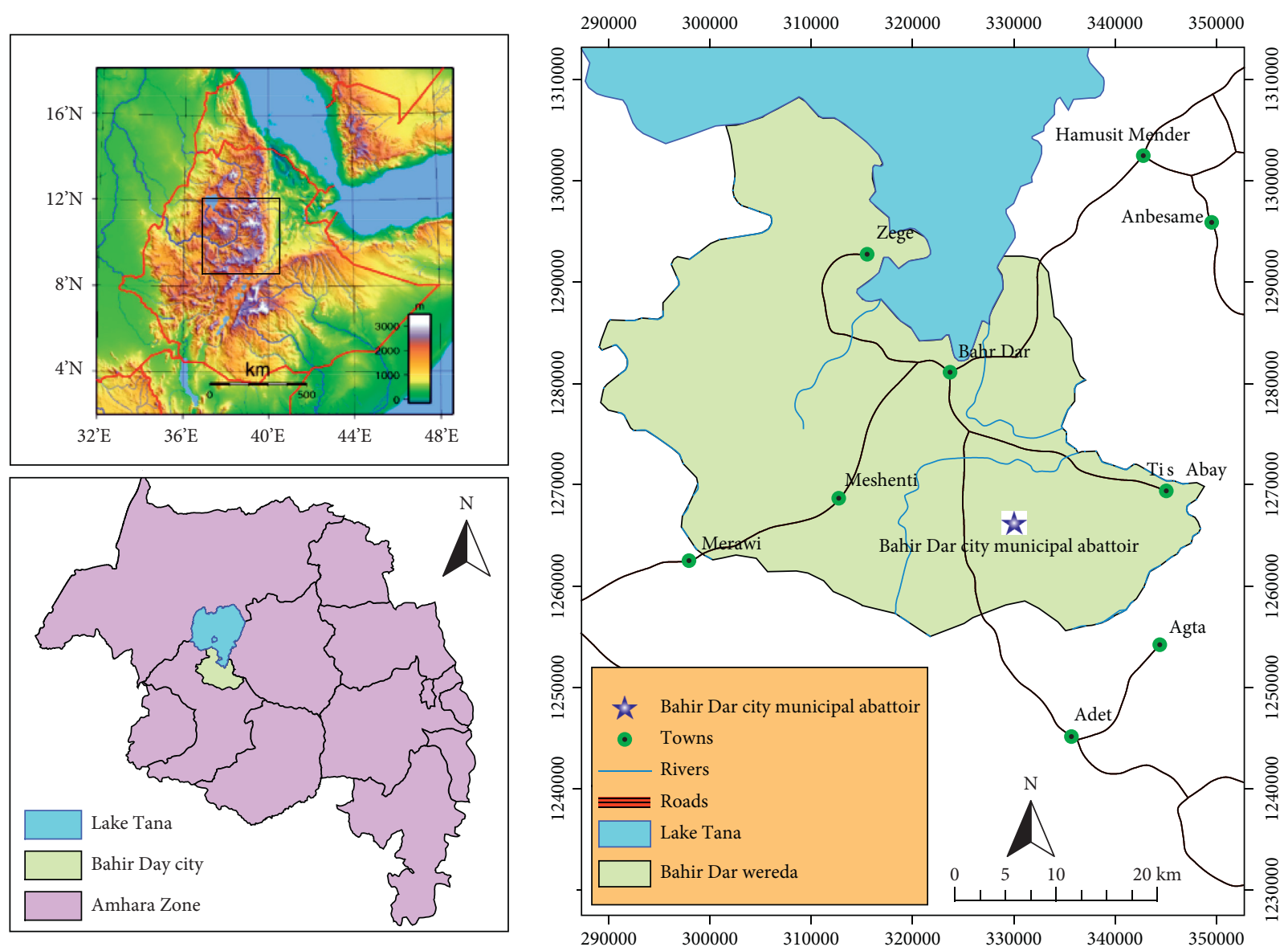

FIgURe 1: A map indicating the location of the study area.

for further processing. Upon arrival, all the samples were stored at $4^{\circ} \mathrm{C}$ until to be processed for isolation and identification. The molecular detection and antimicrobial susceptibility determination were conducted at the Institute of Biotechnology, Addis Ababa University.

2.3. Isolation of E. coli O157:H7. The method was based on enrichment in a selective broth medium (modified Tryptone Soya Broth (TSB) supplemented with novobiocin (Oxoid) $(10 \mathrm{mg} / \mathrm{l}))$. The nonselective pre-enrichment technique was used to effectively recover low levels of stressed E. coli O157: H7. After that, the enrichment broths were prewarmed to prevent cold shocking of the organisms and to slow their initial growth [11, 27]. Then, plating on 1\% sorbitol MacConkey agar (supplemented with tellurite-cefixime supplement (HiMedia) (CT-SMAC)) was incubated at $37^{\circ} \mathrm{C}$ for 24 hours. Nonsorbitol-fermenting (NSF) E. coli (colorless or pale colonies) were considered as presumptive E. coli O157: H7, whereas pinkish colored colonies (sorbitol fermenters) were considered as non-O157:H7 E. coli since E. coli O157: H7 does ferment sorbitol slowly [28].

2.4. Serotyping. All NSF colonies which were presumptive $E$. coli O157:H7 were subjected to slide agglutination with the E. coli $\mathrm{O} 157$ latex test kit according to the manufacturer's instructions. Isolates giving a positive reaction (formed agglutination) to the latex test were considered to be E. coli O157:H7 positive [29]. Once confirmation testing was completed, isolates were stored in a $20 \%$ glycerol TSB solution and frozen for further molecular characterization and conducting antimicrobial susceptibility analysis [30] and were transported and processed at the Institute of Biotechnology, Addis Ababa University.

2.5. Antibiotic Susceptibility Test. The antibacterial susceptibility testing of the isolates was performed using disc diffusion according to [31] using eleven antibiotic discs (all from Oxoid (oxytetracycline $(30 \mu \mathrm{g})$, tetracycline $(30 \mu \mathrm{g})$, chloramphenicol $(30 \mu \mathrm{g})$, ampicillin $(10 \mu \mathrm{g})$, sulphonamides $(30 \mu \mathrm{g})$, ciprofloxacin $(5 \mu \mathrm{g})$, neomycin $(10 \mu \mathrm{g})$, clindamycin $(10 \mu \mathrm{g})$, trimethoprim $(5 \mu \mathrm{g})$, norfloxacin $(10 \mu \mathrm{g})$, and streptomycin $(25 \mu \mathrm{g}))$. The selection criteria for discs depended on the regular use of antimicrobials in the ruminants and their potential public health importance [32].

The antibiotic discs were firmly placed on sterile Mueller-Hinton agar plates previously seeded with a 24hour-old culture of the isolate $(106 \mathrm{CFU} / \mathrm{ml}$ of $0.5 \mathrm{McFar}$ land standard). The plates were incubated at $37^{\circ} \mathrm{C}$ for $24 \mathrm{hr}$, and diameters of zones of inhibition were compared. Multiple antibiotic-resistant isolates were defined as resistance to greater than or equal to three classes of the 
antibiotics tested. Plates were incubated at $37^{\circ} \mathrm{C}$, and the diameter of the zone of growth inhibition was measured with calipers to the nearest millimeter and interpreted accordingly $[22,31]$.

2.6. Detection of Virulence Genes. Standard methods of the boiling method of DNA extraction were carried out $[33,34]$. The sorbitol-negative isolates which were identified by latex agglutination test were examined by the polymerase chain reaction (PCR) (HiMedia Laboratories PLC.) to determine the presence of $s t x 1$, stx 2 , eae, and $h l y A$ virulence genes [21, 22, 34-37]. PCR sequence of primers, their product size, and their amplification conditions are depicted in Table 1.

2.7. Ethical Review. The study protocol was reviewed and approved by the Institutional Review Board of Bahir Dar University, College of Agriculture and Environmental Science, School of Animal Production and Veterinary Medicine. A letter of support was obtained from Bahir Dar University, and official permission was requested from the concerned higher officials, Bahir Dar city Abattoir Administration.

2.8. Data Analysis. All data collected during the study period were checked, coded, and entered into a computer Excel spreadsheet (Microsoft Excel 2013) and analyzed by SPSS software, version 23. Descriptive statistics such as percentages and frequency distribution were applied to quantify magnitude of contamination of carcass, molecular detection levels, and antimicrobial susceptibility profile of the isolates. Pearson's chi-square was applied to measure the difference in the isolation of E. coli O157:H7 by the site of the sampled carcass. A $P$ value $<0.05$ was considered indicative of a statistical significance.

\section{Results}

3.1. Isolation and Identification of E. coli O157:H7. A swab sample was taken from apparently healthy cattle slaughtered in the abattoir. Standard microbiological examination of the swab samples collected from different regions of the carcass (the abdomen (flank), thorax (lateral), and breast (lateral)) and serotyping of the isolated E. coli O157:H7 with latex agglutination revealed the isolation of 25 (8.9\%) strains of E. coli $\mathrm{O} 157: \mathrm{H7}$ organisms out of a total of 280 examined samples. Although swab samples from the thorax region yield the highest isolation rate of the organism, no significant difference $(P>0.05,95 \% \mathrm{CI})$ occurred among the regions of the carcass where the sample was taken (Table 2).

3.2. Detection of Virulence Genes. Out of 25 isolates tested by PCR for the four virulence genes (stx1, stx2, eae, and $h l y A), 1$ (4\%) isolate had all the four virulence genes. Four $(16 \%)$ of the isolates had at least three of the genes in their DNA structure, and $25(100 \%)$ of isolates had at least one of the four virulence genes (Table 3 ).
With regard to each gene, $8(32 \%)$ isolates were positive for stx $1,14(56 \%)$ of the isolates had the stx 2 gene, $5(20 \%)$ isolates had both genes (i.e., stx1 and stx2), 18 (72\%) isolates had the hlyA gene, and only 5 (2\%) isolates had the eae gene. Typical gel images showing the agarose-separated PCR products of the virulence genes are indicated in Figure 2.

\subsection{Antimicrobial Susceptibility Profile of E. coli O157:H7} Isolates. Out of 11 antimicrobials tested for the resistance profile, all isolates were susceptible (100\%) to oxytetracycline, tetracycline, sulphonamides, ampicillin, ciprofloxacin, neomycin, and norfloxacin (Table 4). Resistances to three or more drugs were not detected in any of the isolates. All 25 $(100 \%)$ isolates were resistant to clindamycin, and $3(12 \%)$ isolates were resistant to trimethoprim. In addition, 3 (12\%) isolates showed intermediate susceptibility to streptomycin.

\section{Discussion}

4.1. Isolation and Identification of E. coli O157:H7. The frequency of isolation of E. coli O157:H7 in swab samples taken from the carcass in this study was $8.9 \%$. This result was in agreement with other reports in different countries with $8 \%$ in Debre Zeyit and Modjo [21] and 8.1\% in Modjo, Ethiopia [12], and $9.3 \%$ in Jimma [40], but these data indicated high frequency of occurrence relative to reports from Haramaya University (2.2\%) and Dire Dawa slaughterhouses (4\%) [2] and swab samples taken from the carcass in the Hawassa municipal abattoir (2.7\%) [19], Modjo (4.17\%) [20], China (2.7\%) [41], and Egypt (3.1\%) [42]. On the contrary, it was lower than the culture-based prevalence of $E$. coli isolates $(22.2 \%)$ from meat samples collected from the Mekelle municipal abattoir in northern Ethiopia [43]. This varied prevalence in various studies might be due to ecological variations among the study sites and the difference in the slaughtering procedure in different sites [12, 40]. Any detection of E. coli O157:H7 in meat is considered unacceptable [44]. However, there are no regulations in Ethiopia to protect meat consumers from foodborne pathogens such as E. coli O157:H7 [23].

4.2. Detection of Virulence Genes. Several virulence factors have been associated with the pathogenicity of NSF E. coli O157:H7. These factors include production of at least one of two Shiga toxins (stx1 and/or stx2), intimin (eae), and enterohemolysin (EHEC-hlyA) [22]. In the present study, we investigated the existence of these four virulence genes in the isolated E. coli O157:H7 strains. All (100\%) of the isolates had at least one of the four virulence genes (stx1, stx2, eae, and $h l y A)$ in their DNA. Although this report was not in agreement with Kalin et al. [35] in which no virulence genes were detected except the eae gene, it was in line with the report from Turkey [45] in which all the isolates harbored the four virulence genes.

The pathogenicity of E. coli O157:H7 is attributed to the production of Shiga toxins (stx 1 and stx2), previously known as verocytotoxin because of their toxicity on Vero cells $[46,47]$. PCR verified the presence of the stx 2 gene at the 
TABLE 1: Sequence of primers, their product size, and their annealing temperature.

\begin{tabular}{|c|c|c|c|c|c|}
\hline Gene & Primer & Sequence $\left(5^{\prime}-3^{\prime}\right)$ & Primer length (bp) & Annealing temperature $\left({ }^{\circ} \mathrm{C}\right)$ & Reference \\
\hline \multirow[b]{2}{*}{ stx 1} & EVS-1 & F: ATCAGTCGTCACTCACTGG & \multirow{2}{*}{110} & \multirow{2}{*}{55} & \multirow{2}{*}{ [38] } \\
\hline & EVC-2 & R: CTGCTGTCACAGTGACAAA & & & \\
\hline \multirow{2}{*}{ stx 2} & EVT-1 & F: CAACACTGGATGATCTCAG & \multirow{2}{*}{350} & \multirow{2}{*}{55} & \multirow{2}{*}[38]{} \\
\hline & EVT-2 & R: CCСССТCAACTGCTAATA & & & \\
\hline \multirow{2}{*}{ hlyA } & Hly-1 & F: GGTGCAGCAGAAAAAGTTG & \multirow{2}{*}{165} & \multirow{2}{*}{45} & \multirow{2}{*}[39]{} \\
\hline & Hly-1 & R: CCACGTCGTCTTTTTCAACA & & & \\
\hline \multirow{2}{*}{ eae } & EAE-1 & F: AAACAGGTGAAACTGTTGCC & \multirow{2}{*}{490} & \multirow{2}{*}{55} & \multirow{2}{*}[20]{} \\
\hline & EAE-2 & R: CTCTGCAGATTAACCTCTGC & & & \\
\hline
\end{tabular}

EAE: effacing and attaching; EV: verocytotoxin; stx: Shiga toxin; bp: base pair; F: forward primer; R: reverse primer; $h l y A$ : hemolysin.

TABLE 2: Number of positive samples per region of the carcass sampled.

\begin{tabular}{lccc}
\hline Carcass region & Number of samples taken & Number (\%) of positive samples & $\chi^{2}$ value \\
\hline Abdomen & 93 & $7(28)$ & $P$ value \\
Thorax & 94 & $11(44)$ & 1.407 \\
Breast & 93 & $7(28)$ & 0.495 \\
Total & 280 & $25(100)$ & \\
\hline
\end{tabular}

TABLE 3: Virulence gene profile of the isolates.

\begin{tabular}{lcccc}
\hline Isolates & $s t x 1$ & $s t x 2$ & eae & hlyA \\
\hline 1 & + & - & - & + \\
2 & - & + & - & - \\
3 & - & - & + & - \\
4 & - & + & - & + \\
5 & - & + & - & + \\
6 & + & + & - & + \\
7 & - & - & + & - \\
8 & - & + & + & - \\
9 & - & + & - & + \\
10 & + & - & - & + \\
11 & + & + & - & + \\
12 & - & - & + & + \\
13 & - & - & - & + \\
14 & - & + & - & + \\
15 & - & + & - & + \\
16 & + & + & - & + \\
17 & - & - & - & + \\
18 & + & - & - & - \\
19 & + & + & - & + \\
20 & - & + & - & - \\
21 & - & - & - & + \\
22 & - & + & - & - \\
23 & + & + & + & + \\
24 & - & - & - & + \\
25 & - & - & - & + \\
Total & - & & 5 & 18 \\
\hline & & + & & +
\end{tabular}

expected molecular size of $350 \mathrm{bp}$ in $56 \%$ isolates which were more than stx 1 (only $32 \%$ isolates harbored it). This finding was in agreement with studies in California [47], China [41], Egypt [42], and Modjo, Ethiopia [20]. The strains carrying stx 2 are potentially more virulent than those carrying stx 1 or even strains carrying both st $x 1$ and stx $2[22,42,47]$. On the contrary, $36 \%$ of the isolates do not have either of the two Shiga toxin-producing genes. This result was in agreement with the research from Ohio, United States of America, with 23\% stx-negative E. coli O157:H7 [48]. The role of stxnegative E. coli O157:H7 in the ecology and epidemiology of

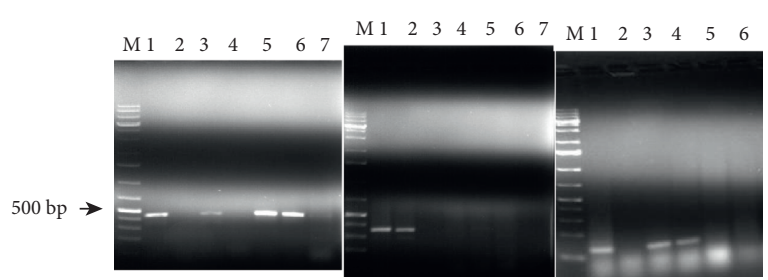

Figure 2: Agarose gel electrophoresis of amplified products for eae (490 bp), stx2 (349 bp), and stx1 (110 bp) of E. coli O157:H7 isolates, respectively. Key: lane M: DNA ladder, lane 1: known positive control (taken from previous works), lanes 2-6: samples (those which have a band are positive to the gene), and lane 7 : negative control.

the human disease causing STEC is unknown. Although stx is considered to be the essential virulence factor of STEC, it has been suggested that stx-negative O157:H7 can cause diarrhea and HUS [48].

In the present study, $8 \%$ of the isolates have both $h l y A$ and eae genes. The enterohemorrhagic hemolysin $h l y A$ makes adherence possible for eae-negative strains. When both $h l y A$ and eae genes are present, this is an indicator for increased pathogenicity [10]. In addition, $20 \%$ of the isolates harbored the eae gene in our study. The gene was mostly reported in STEC strains associated with severe human illnesses such as bloody diarrhea and HUS. However, STEC strains lacking the eae gene have been reported to cause outbreaks [42, 47]. In addition, hly $A$ is carried on the plasmid, and the bacteria can lose the gene together with the plasmid upon subsequent culturing, and this could be one reason for not detecting $h l y A$ in all the isolates [49].

4.3. Antimicrobial Susceptibility Profiles of the Isolates. The E. coli O157:H7 strains isolated in this study were all found to be susceptible to most antimicrobials tested. Similar findings have been reported by other researchers [12, 19, 21]. However, resistant strains do exist mainly against clindamycin and trimethoprim. Clindamycin is effective against 
TABle 4: Antimicrobial susceptibility profile of E. coli O157:H7 isolated from carcass swab samples.

\begin{tabular}{|c|c|c|c|c|}
\hline \multirow{2}{*}{ Drugs } & \multirow{2}{*}{ Concentration $(\mu \mathrm{g})$} & \multicolumn{3}{|c|}{ Frequency of resistance and susceptible $E$. coli $\mathrm{O} 157: \mathrm{H} 7$ isolates } \\
\hline & & Resistant & Intermediate & Susceptible \\
\hline Oxytetracycline & 30 & $0(0 \%)$ & $0(0 \%)$ & $25(100 \%)$ \\
\hline Tetracycline & 30 & $0(0 \%)$ & $0(0 \%)$ & $25(100 \%)$ \\
\hline Sulphonamides & 30 & $0(0 \%)$ & $0(0 \%)$ & $25(100 \%)$ \\
\hline Ampicillin & 10 & $0(0 \%)$ & $0(0 \%)$ & $25(100 \%)$ \\
\hline Ciprofloxacin & 5 & $0(0 \%)$ & $0(0 \%)$ & $25(100 \%)$ \\
\hline Neomycin & 10 & $0(0 \%)$ & $0(0 \%)$ & $25(100 \%)$ \\
\hline Clindamycin & 10 & $25(100 \%)$ & $0(0 \%)$ & $0(0 \%)$ \\
\hline Trimethoprim & 5 & $3(12 \%)$ & $0(0 \%)$ & $22(88 \%)$ \\
\hline Norfloxacin & 10 & $0(0 \%)$ & $0(0 \%)$ & $25(100 \%)$ \\
\hline Streptomycin & 25 & $0(0 \%)$ & $3(12 \%)$ & $22(88 \%)$ \\
\hline Chloramphenicol & 10 & $0(0 \%)$ & $0(0 \%)$ & $25(100 \%)$ \\
\hline
\end{tabular}

Gram-positive and anaerobic bacteria, but it is not effective against E. coli [50]. Antimicrobial resistance emerges from the use of antimicrobials in animals and humans and the subsequent transfer of resistance genes and bacteria among animals, humans, animal products, and the environment [51].

Intermediate resistance to streptomycin was also observed, while this result was opposite to a previous work conducted by Tilahun and Engdawork [52] from Hawassa who isolated E. coli O157:H7 from fish, and tolerance to streptomycin had not been detected in the study, but only moderate resistance was detected. Although streptomycin is one of the most commonly available drugs for use among livestock in Ethiopia, it is readily available in different dosage forms and in combination with other antimicrobials and vitamins [23].

Electiveness of treatments and ability to control infectious diseases in both animals and humans may be severely hampered. The recommended management of an infection mainly relies on supportive therapy and hydration [18]. Some of the drugs we tested such as ampicillin, sulfonamides, and trimethoprim can increase the risk of HUS; and thus, they are not recommended for the treatment of infections caused by E. coli O157:H7 [53].

Abattoir is one of the food industries that contributes to the problem of possible foodborne diseases and potential health hazards associated with food unless the principles of food hygiene are implemented $[44,54]$. This study finding indicates the presence of microbiological contamination of indicator bacteria in beef meat in Bahir Dar city, and thus it is microbiologically unsafe for human consumption.

The limitation of this study was that it assessed only abattoir carcasses, excluding butcher shops and restaurants where contamination can occur at these stages. There may be backyard slaughter and cross-contamination in the process. The reason was due to the limited time frame and insufficient resources while conducting the research.

\section{Conclusion and Recommendations}

In general, from 280 swab samples taken from the carcass of cattle slaughtered at the Bahir Dar municipal abattoir, 25 (8.9\%) samples were found contaminated with virulent E. coli $\mathrm{O} 157: \mathrm{H7}$. All the isolated strains of E. coli $\mathrm{O} 157: \mathrm{H7}$ were able to elicit at least one of the virulence genes (stx1, stx2, eae, and $h l y A$ ) subjected for PCR virulence gene detection which highlights the potential threat to public health both as a result of the contamination of the carcass and harboring of virulence genes. Thus, preventive approaches should be followed to control $E$. coli O157:H7 contamination in cattle slaughtering and processing chain by imposing strict hygienic meat processing practices in the Bahir Dar municipal abattoir. Intensive training should be given to those personnel working in municipal slaughterhouses to ensure the hygienic practices during slaughtering of animals. Improvement of facilities should be implemented with closure of substandard facilities and focusing resources on fewer facilities to improve meat hygiene in this resourcelimited setting. Further detailed epidemiological and molecular studies should be carried out on E. coli O157:H7 in different abattoirs and species of food animals in the country. In this study, even if most of the isolates used are sensitive to the antimicrobials used, some isolates showed moderate resistance to trimethoprim and streptomycin. Thus, the status of antibiotic resistance in meat-borne pathogens such as E. coli O157:H7 should be monitored regularly.

\section{Data Availability}

The raw data used and/or analyzed during this study are available from the first author upon reasonable request.

\section{Ethical Approval}

This study was conducted on the carcass of the abattoir. In addition, this study protocol was reviewed and approved by the Institutional Review Board of Bahir Dar University.

\section{Conflicts of Interest}

All authors declare no conflicts of interest.

\section{Authors' Contributions}

HY and TS designed the proposal, participated in the coordination and management of the study, collected, tested, and analyzed the data, and drafted the article. BA and TS 
participated in study design, scientific advising of the overall work, and edition of the article. All authors read and approved the final manuscript.

\section{Acknowledgments}

The authors would like to thank Amhara Public Health Institute, Microbiology Laboratory, and Addis Ababa University, Institute of Biotechnology, for their material and the laboratory support. Also, they would like to thank Addis Ababa University, Institute of Biotechnology, and Ethiopian Biotechnology Institute for their joint financial support (ref. no. 17.2/0409/2019).

\section{References}

[1] P. Fratamico, K. Bhunia, and J. Smith, Foodborne Pathogens: Microbiology and Molecular Biology, Caister Academic Press, Wymondham, UK, 2005.

[2] S. Mengistu, E. Abayneh, and D. E. Shiferaw, "E. coli O157: H7 and salmonella species: public health importance and microbial safety in beef at selected slaughter houses and retail shops in eastern Ethiopia," Journal of Veterinary Science \& Technology, vol. 8, p. 468, 2017.

[3] N. Heredia and S. García, "Animals as sources of food-borne pathogens: a review," Animal Nutrition, vol. 4, no. 3, pp. 250-255, 2018.

[4] Z. Ayana, M. Yohannis, and Z. Abera, "Food borne bacterial diseases in Ethiopia," Academic Journal of Nutrition, vol. 4, no. 1, pp. 62-76, 2015.

[5] J. E. Lee, J. Reed, M. S. Shields, K. M. Spiegel, L. D. Farrell, and P. P. Sheridan, "Phylogenetic analysis of shiga toxin 1 and shiga toxin 2 genes associated with disease outbreaks," $B M C$ Microbiology, vol. 7, no. 1, p. 109, 2007.

[6] A. Assefa, "Prevalence of E. coli O157: H7 in foods of animal origin in Ethiopia: a meta-analysis," Cogent Food \& Agriculture, vol. 5, pp. 164-2981, 2019.

[7] K. Rahal, N. Kazzi, F. Nassar, and G. Matar, "E. coli O157: H7 clinical aspects and novel treatment approaches," Frontiers in Cellular and Infection Microbiology, vol. 2, no. 138, p. 1, 2012.

[8] M. Javadi and B. Saeid, "Genotype cluster analysis in pathogenic E. coli isolates producing different CDT types," Journal of Pathogens, vol. 127, p. 8, 2016.

[9] H. Hizlisoy, S. Al, N. Ertaş Onmaz, Y. Yildirim, Z. Gönülalan, and K. S. Gümüşsoy, "Antimicrobial resistance profiles and virulence factors of Escherichia coliO157 collected from a poultry processing plant*," Turkish Journal of Veterinary and Animal Sciences, vol. 41, pp. 65-71, 2017.

[10] E. G. Freitas Filho, M. R. A. Ferreira, J. F. N. Pinto, F. R. Conceição, and C. N. Moreira, "Enterohemorrhagic Escherichia coli O157: H7 from healthy dairy cattle in midwest Brazil: occurrence and molecular characterization," Pesquisa Veterinária Brasileira, vol. 34, no. 1, pp. 24-28, 2014.

[11] Organization International Epizootics (OIE), CytotoxigenicEscherichiacoli, Organization International Epizootics (OIE), Paris, France, 2018.

[12] G. Mersha, D. Asrat, B. M. Zewde, and M. Kyule, "Occurrence of E. coli O157: H7 in faces, skin and carcasses from sheep and goats in Ethiopia," Letters in Applied Microbiology, vol. 50, no. 1, pp. 71-76, 2009.

[13] R. Abdissa, W. Haile, A. T. Fite et al., "Prevalence of Escherichia coli O157: $\mathrm{H} 7$ in beef cattle at slaughter and beef carcasses at retail shops in Ethiopia," BMC Infectious Diseases, vol. 17, no. 1, p. 277, 2017.

[14] T. A. Welday, L. T. Weldeabezgi, K. A. Seyoum, G. Tafere, and H. H. Kassegn, "Salmonella and risk factors for the contamination of cattle carcass from abattoir of Mekelle city, Ethiopia," Cogent Food \& Agriculture, vol. 4, Article ID 1557313, 2018

[15] L. Grispoldi, M. Karama, C. Hadjicharalambous et al., "Bovine lymph nodes as a source of Escherichia coli contamination of the meat," International Journal of Food Microbiology, vol. 331, Article ID 108715, 2020.

[16] L. Baoguang, L. Huanli, and W. Weimin, "Multiplex real-time PCR assay for detection of E. coli O157: H7 and screening for non O157 shiga toxin producing E. coli," BMC Microbiology, vol. 17, p. 215, 2017.

[17] M. Shecho, N. Thomas, J. Kemal, and Y. Muktar, "Cloacael, carriage and multidrug resistance Escherichia coli O157: H7 from poultry farms eastern Ethiopia," Journal of Veterinary Medicine A, vol. 9, 2017.

[18] N. Disassa, B. Sibhat, S. Mengistu, Y. Muktar, and D. Belina, "Prevalence and antimicrobial susceptibility pattern of E. coli O157: H7 isolated from traditionally marketed raw cow milk in and around Asosa town, western Ethiopia," Veterinary Medicine International, vol. 7, 2017.

[19] B. Atnafie, D. Paulos, M. Abera et al., "Occurrence of Escherichia coli O157: H7 in cattle feces and contamination of carcass and various contact surfaces in abattoir and butcher shops of Hawassa, Ethiopia," BMC Microbiology, vol. 17, no. 1, p. 24, 2017.

[20] S. Abreham, A. Teklu, E. Cox, and T. Sisay Tessema, "Escherichia coli O157: H7: distribution, molecular characterization, antimicrobial resistance patterns and source of contamination of sheep and goat carcasses at an export abattoir, Mojdo, Ethiopia," BMC Microbiology, vol. 19, no. 1, p. 215, 2019.

[21] A. Hiko, D. Asrat, and G. Zewde, "Occurrence of Escherichia coli O157: H7 in retail raw meat products in Ethiopia," Journal of Infection in Developing Countries, vol. 2, no. 5, pp. 389-393, 2008.

[22] C. Fashina, G. Babalola, and M. Osunde, "Prevalence and molecular characterization of E. coli O157: H7 isolated from water bodies in ile-ife and environs," Journal of Bacteriology \& Parasitology, vol. 9, p. 340, 2018.

[23] F. Dulo, A. Feleke, B. Szonyi, R. Fries, M. P. Baumann, and D. Grace, "Isolation of multidrug-resistant Escherichia coli O157 from goats in the Somali region of Ethiopia: a crosssectional, abattoir-based study," PLoS One, vol. 10, no. 11, Article ID e0142905, 2015.

[24] Bureau of Agriculture and Rural Development (BoARD), Amhara Region, Statistics Section 2005, Bureau of Agriculture and Rural Development (BoARD), Bahir Dar, Ethiopia, 2005.

[25] A. Nuru, A. Zewude, T. Mohammed et al., "Nontuberculosis mycobacteria are the major causes of tuberculosis like lesions in cattle slaughtered at Bahir Dar abattoir, northwestern Ethiopia," BMC Veterinary Research, vol. 13, no. 1, p. 237, 2017.

[26] International Organization for Standardization, Microbiology of Food Animal, Feeding Stuffs-Carcass Sampling for Microbiological Analysis, International Organization for Standardization, Geneva, Switzerland, 2005.

[27] F. A. Clifton-Hadley, "Detection and diagnosis of Escherichia coli $\mathrm{O} 157$ and other verocytotoxigenic E. coli in animal faeces," Reviews in Medical Microbiology, vol. 11, no. 1, pp. 47-60, 2000. 
[28] International Organization for Standardization, Microbiology of Food and Animal Feeding Stuff-Horizontal Method for the Detection of E. coli O157, International Organization for Standardization, Geneva, Switzerland, 2001.

[29] C. Kiranmayi and N. Krishnaiah, "Detection of Escherichia coli O157: $\mathrm{H} 7$ prevalence in foods of animal origin by cultural methodsand PCR technique," Veterinary World, vol. 1, pp. 13-16, 2010.

[30] K. D. Childs, C. A. Simpson, W. Warren-serna et al., "Molecular characterization of Escherichia coli O157: H7 hide contamination routes: feedlot to harvest," Journal of Food Protection, vol. 69, no. 6, pp. 1240-1247, 2006.

[31] Clinical and Laboratory Standards Institute, Performance Standards for Antimicrobial Susceptibility Testing: Twenty Second Informational Supplement: CLSI Document, Clinical and Laboratory Standards Institute, Wayne, PA, USA, 28th edition, 2018.

[32] M. Hamid, Y. Tefera, T. Eguale, and Y. Worku, "Escherichia coli O157: H7: prevalence, identification and antimicrobial resistance in cattle slaughter at Addis Ababa municipal abattior, Ethiopia," International Journal of Advanced Research in Biological Sciences, vol. 5, no. 10, pp. 136-146, 2018.

[33] J. L. Wasilenko, P. M. Fratamico, N. Narang et al., "Influence of primer sequences and DNA extraction method on detection of non-O157 shiga toxin-producing Escherichia coli in ground beef by real-time PCR targeting the eae, stx, and serogroup-specific genes," Journal of Food Protection, vol. 75, no. 11, pp. 1939-1950, 2012.

[34] F. Firoozeh, M. Saffari, F. Neamati, and M. Zibaei, "Detection of virulence genes in Escherichia coli isolated from patients with cystitis and pyelonephritis," International Journal of Infectious Diseases, vol. 29, pp. 219-222, 2014.

[35] R. Kalin, H. Ongor, and H. Cetinkaya, "Isolation and molecular characterization of ecoli $\mathrm{O} 157$ from broiler and human samples," Foodborne Pathogens and Disease, vol. 9, no. 4, 2012.

[36] J. Amani, A. Ahmadpour, A. A. Imani Fooladi, and S. Nazarian, "Detection of E. coli O157: H7 and Shigella dysenteriae toxins in clinical samples by PCR-ELISA," Brazilian Journal of Infectious Diseases, vol. 19, no. 3, pp. 278-284, 2015.

[37] Y. Yakubu, A. Shuaibu, A. Ibrahim, U. Hassan, and R. Nwachukwu, "Risk of shiga toxigenic Escherichia coli O157: H7 infection from raw and fermented milk in sokoto metropolis, Nigeria," Journal of Pathogens, vol. 5, 2018.

[38] M. Ashgan, A. Abdullah, M. Adel et al., "Molecular characterization of E. coli O157: $\mathrm{H} 7$ recovered from meat and meat products relevant to human health in Riyadh, Saudi Arabia," Saudi Journal of Biological Sciences, vol. 22, pp. 725-729, 2015.

[39] M. Kargar and M. Homayoon, "Prevalence of shiga toxins (stx1, stx2), eaeA and hly genes of Escherichia coli O157: H7 strains among children with acute gastroenteritis in southern of Iran," Asian Pacific Journal of Tropical Medicine, vol. 8, no. 1, pp. 24-28, 2015.

[40] A. F. Haile, D. Kebede, and A. K. Wubshet, "Prevalence and antibiogram of Escherichia coli O157 isolated from bovine in Jimma, Ethiopia: abattoirbased survey," Ethiopian Veterinary Journal, vol. 21, no. 2, pp. 109-120, 2017.

[41] S. Wang, S. Zhang, Z. Liu et al., "Molecular characterization of enterohemorrhagic E. coli $\mathrm{O} 157$ isolated from animal fecal and food samples in eastern China," Science World Journal, vol. 7, 2014.

[42] H. Ahmed, E. MacLeod, R. El Bayomi, R. Mohsen, and A. Nassar, "Molecular characterization of Escherichia coli
O157: H7 and non-O157 shiga toxin producing E. coli from retail meat and humans," Zagazig Veterinary Journal, vol. 45, no. 3, pp. 250-261, 2017.

[43] M. Haileselassie, H. Taddele, K. Adhana, and S. Kalayou, "'Source (s) of contamination of "raw" and "ready-to-eat" foods and their public health risks in Mekelle city, Ethiopia," Journal of Food and Agricultural Sciences, vol. 2, pp. 20-29, 2012.

[44] FAO and WHO, Codex Alimentarius, Food Hygiene Basic Texts, Codex Alimentarius Commission, Rome, Italy, Fourth edition, 2009.

[45] H. Kalender and A. Kilic, "Molecular characterization of shiga toxin-producing Escherichia coli O157: H7 isolates from cattle in eastern Turkey," Veterinary Medicine, vol. 61, no. 12, pp. 663-668, 2016.

[46] E. Rahimi, H. Momtaz, M. Anari, M. Alimoradi, M. Momen, and M. Riahi, "Isolation and genomic characterization of E. coli O157: NM and E. coli O157: H7 in minced meat and some traditional dairy products in Iran," African Journal of Biotechnology, vol. 11, pp. 2328-2332, 2012.

[47] C. Kilonzo, E. R. Atwill, R. Mandrell, M. Garrick, V. Villanueva, and B. R. Hoar, "Prevalence and molecular characterization of Escherichia coli O157: H7 by multiplelocus variable-number tandem repeat analysis and pulsedfield gel electrophoresis in three sheep farming operations in California," Journal of Food Protection, vol. 74, no. 9, pp. 1413-1421, 2011.

[48] A. N. Wetzel and J. T. LeJeune, "Isolation of Escherichia coli O157: H7 strains that do not produce shiga toxin from bovine, avian and environmental sources," Letters in Applied Microbiology, vol. 45, no. 5, pp. 504-507, 2007.

[49] M. Ferdous, Shiga toxin-producing E. coli (STEC) from humans in the Netherlands: novel diagnostic approach, molecular characterization and phylogenetic background, $\mathrm{PhD}$ Thesis, University of Groningen, Groningen, Netherlands, 2017.

[50] K. Kishi, K. Hirai, K. Hiramatsu, T. Yamasaki, and M. Nasu, "Clindamycin suppresses endotoxin released by ceftazidimetreated Escherichia coli O55: B5 and subsequent production of tumor necrosis factor alpha and interleukin-1 $\beta$," Antimicrobial Agents and Chemotherapy, vol. 43, no. 3, pp. 616-622, 1999.

[51] T. Bekele, G. Zewde, G. Tefera, A. Feleke, and K. Zerom, "Escherichia coli O157: H7 in raw meat in Addis Ababa, Ethiopia: prevalence at an abattoir and retailers and antimicrobial susceptibility," International Journal of Flow Control, vol. 1, p. 4, 2017.

[52] A. Tilahun and A. Engdawork, "Isolation, identification and antimicrobial susceptibility profile of E. coli (O157: H7) from fish in lake Hawassa, southern Ethiopia," International Journal of Veterinary Science \& Technology, vol. 3, no. 1, pp. 13-19, 2019.

[53] A. F. Beyi, A. T. Fite, E. Tora et al., "Prevalence and antimicrobial susceptibility of Escherichia coli O157 in beef at butcher shops and restaurants in central Ethiopia," BMC Microbiology, vol. 17, no. 1, p. 49, 2017.

[54] M. Yakubu, M. Bhagavandas, and U. Yusha'u, "Study of knowledge, attitude and practices regarding hygiene among abattoir workers in Kano state metropolitan, Nigeria," International Journal of Science and Research, vol. 4, no. 1, pp. 2319-7064, 2013. 